\title{
Quality of Life of Chronic Haemodialytic Patients at Cotonou Teaching Hospital (BENIN)
}

\author{
Elhadji Fary Ka ${ }^{1}$, Jacques Vigan ${ }^{2 *}$, Ahmed Tall Lemrabott ${ }^{1}$, Noriace Excelle Zohoun ${ }^{2}$, \\ Mohamedou Moustapha Cissé ${ }^{1}$, Séraphin Ahoui², Maria Faye1, Younoussa Keita1, \\ Khodia Fall'1, Bruno Léopold Agboton ${ }^{2}$, Abdou Niang'1, Boucar Diouf ${ }^{1}$ \\ ${ }^{1}$ Nephrology Department, Aristide Le Dantec Hospital, Dakar, Senegal \\ ${ }^{2}$ Nephrology and Hemodialysis Clinic, Hubert Koutoukou Maga Teaching Hospital, Cotonou, Benin \\ Email: ${ }^{*}$ viques2@yahoo.fr
}

Received 26 October 2014; revised 23 November 2014; accepted 7 December 2014

Copyright (C) 2014 by authors and Scientific Research Publishing Inc.

This work is licensed under the Creative Commons Attribution International License (CC BY).

http://creativecommons.org/licenses/by/4.0/

(c) (i) Open Access

\begin{abstract}
Introduction: The objectives of this work were to assess haemodialytic patients' quality of life (QoL) and to identify factors affecting this QoL. Patients and Methods: It was a three (03) month monocentric and transversal study (from October 24, 2011 to January 27, 2012) conducted in the haemodialysis unit at Hubert Koutoukou Maga Teaching Hospital (CNHU-HKM) in Cotonou. Patients included were residents of Benin, aged 18 years and above, chronic haemodialysis in this unit for over 3 months, and willfully gave their consent. Quality of life was evaluated using questionnaire on Kidney Disease Quality of Life Short-Form French version 1.2 (KDQoL-SF 36). Epidemiological data, nephropathy etiologies and purification parametres were recorded in patients files. Data statistical analysis was performed using SPSS software 11.5. Results: In total 131 patients were involved in the study. The average age was $50.27 \pm 12.17$ years with a sex ratio of 1.69. Nephroangiosclerosis was the 1st cause. Most patients $128(97.71 \%)$ received two haemodialysis sessions on weekly basis. The Average Overall Score (AOS) based respectively on SF 36 and KDQoL was 48.55 and 58.55. The average of both SF 36 and KDQoL AOS was 53.55. Factors affecting hemodialytic patients quality of life were vitality, limitations related to mental health and physical condition, burden of kidney disease, effect of the disease on daily life and occupational status. The study revealed that: Patients education level was correlated with vitality $(p<0.017)$; The number of haemodialyses sessions was correlated with the consequences of kidney disease on daily life $(p<0.025)$. Conclusion: It is necessary to strengthen the staff by providing a psychologist and a dietician and also build new haemodialysis centres.
\end{abstract}

\section{Keywords}

Quality of Life, Haemodialysis Patients, Chronic Kidney Disease, Benin

\footnotetext{
${ }^{*}$ Corresponding author.
} 


\section{Introduction}

Chronic kidney disease is the consequence of gradual and definite loss of kidneys functions. It is secondary to irreversible lesion of the kidney parenchyma [1]. At the terminal phase, the treatment uses kidney substitution techniques such as haemodialysis, peritoneal dialysis, in the absence of kidney transplant. Haemodialysis implies patient's short and long term constraints, despite countless progress made in recent years.

For the past few years, in the field of health, quality of life assessment has become widespread. This is one of the reasons the Kidney Disease and Quality of Life-Short Form (KDQoL-SF) has been proposed as an instrument for the assessment of haemodialytic patients' quality of life [2]. It is intended to measure both the impact of kidney disease and its treatment on the daily life of patients and their level of satisfaction [3]. The concept of "quality of life" is a very important topic in the sense that, from a subjective point of view its study helps to know the impact of diseases on patients' life [4].

In developed countries, haemodialysis care is well codified and abides by the recommendations set by learned societies. In Africa, it is not the case in all countries, because of the poorly equipped technical facilities. If hemodialytic patients' quality of life has thoroughly been studied in some African countries particularly in South and North African Countries, it is the contrast in sub-Saharan Africa where dialysis is not yet accessible to all patients and is therefore scarcely appreciated.

In West Africa, particularly in Senegal, a study has been made in Dakar on this theme in 2008 [5]. In Benin, it is the daily conventional haemodialysis that is practiced. Conventional haemodialysis corrects the renal failing and the hydroelectrolytics disorders; but it's little tolerated, and is not bound to a reduction of mortality. It's freely provided by the Government, but no study has been made so far on chronic haemodialytic patient's quality of life. Factors that are affecting their quality of life are unknown. That is why this study having the objectives below has been initiated:

General Objective:

Assessing haemodialytic patients' quality of life at CNHU-HKM of Cotonou and their determinants. Specific Objectives:

- Assessing haemodialytic patients' quality of life in CNHU-HKM;

- Identifying factors that affect haemodialytic patients' quality of life;

- Determining the correlation between quality of life domains and epidemioclinical characteristics.

\section{Patients and Methods}

This work has been conducted in the haemodialysis unit at Hubert Koutoukou Maga Teaching Hospital (CNHUHKM) in Cotonou, within the Nephrology-Haemodialysis University Hospital. It was a three (03) month monocentric and transversal study from October 24, 2011 to January 27, 2012 using self completed questionnaire for patients. Patients included in the study were residents of Benin, aged 18 years and above, chronic haemodialysis in the unit for over 3 months, and willfully gave their consent.

Quality of life was evaluated using Kidney Disease Quality of Life Short-Form French version 1.2 (KDQoLSF) [2]. It was a self completed questionnaire comprising 79 items and made up of 2 modules.

A generic module: Short-Form (SF-36) made-up of 36 questions grouped into eight domains namely:

- General health (D1);

- Physical activity (D2);

- Limitations due to physical conditions (D3);

- Limitations due to mental state (D4);

- Life and relationships with others (D5);

- Physical pain (D6);

- Vitality (D7);

- Mental health (D8).

These eight domains were also divided into 2 dimensions:

- Physical health dimension was in correlation with "general health", "physical activities", "limitations due to physical activity", "physical pain”, and "vitality";

- Mental health dimension was in correlation with "limitations due to mental activity", "life and relationship with others" and "mental health".

A specific module adapted to kidney pathology, comprising 43 items and divided into 11 domains: 
- Burden of kidney disease (D9);

- Quality of the immediate circle (D10);

- Cognitive functions (D11);

- Symptoms and problems (D12);

- Effects of the disease on daily life (D13);

- Quality of sexual activity (D14);

- Sleep (D15);

- Family and friendly relationship (D16);

- Occupational status (D17);

- Patient's satisfaction (D18);

- Encouragement from dialysis team (D19).

These 19 domains were also divided into 04 dimensions:

- A physical health dimension in correlation with "general health”, "physical functioning”, "limitations due to physical activity", "physical pain”, "vitality” and "occupational status";

- A mental health dimension in correlation with "limitations due to mental activity", "life and relationship with others" "mental health", "quality of the immediate circle", "burden of kidney disease";

- A dialysis specific dimension in correlation with "cognitive functions", "symptoms and problems", "effects of the disease on daily life", "quality of sexual activity" and "sleep";

- A dimension related to patient's care satisfaction along with a question concerning "patient satisfaction" as well as "encouragement from dialysis team".

Scoring of answers was based on a 0 to 100 scale, whereby 0 represented the worst quality of life and 100 the best. An average score was calculated for each domain (DAS) to help identify most affected domains, based on the following formula [(100/S-s) * (Y-s)].

" $\mathrm{S}$ " being the maximum score that an individual might have in the field, "s" the minimum score and $\mathrm{Y}$ is the patient score in the domain.

Furthermore, an average score was calculated for each SF-36 and KDQoL dimension. The overall average score (OAS) was obtained through the calculation of the quotations average; the higher the score, the better the quality of life.

The interpretation of our results was made on the basis of 50 as average for the DAS.

Patients had to fill out the questionnaire by themselves, though sometimes they are assisted by the only one doctor available to either help patients check their chosen answers or translate in local dialect for uneducated patients. The assistance offered by this doctor complied with the recommendations of KDQoL. The formulations in the local dialect have been selected and validated by the research team so as to minimize biases. Epidemiological characteristics (age, sex, level of education, occupational status, marital status, standard of living), etiologies of nephropathy, and dialysis related parametres (number of haemodialyses sessions on weekly basis, vascular access) were filled out by the doctor through each patient's medical record. The standard of living was evaluated on the basis of housing stress, education challenges, lack of financial resources, and poor access to health care. With regard to chronic kidney disease patients, the lack of one of these elements taken separately was regarded as a sign of underprivileged life conditions (UNDP, 2006). On that basis, high, average and low standards of living were clearly defined.

Data were recorded and analyzed using SPSS software 11.5. Univariate and bivariate analyzes were conducted, and 0.05 was the adopted threshold of significance.

\section{Results}

In total, 133 patients met our inclusion criteria. Out of that figure, there was 1 refusal and 1 withdrawal during our investigation, so this brings the figure to 131 patients who effectively took part in the study.

\subsection{Characteristics of the Population}

\subsubsection{Socio-Economic Characteristics of the Study Population}

The average age of patients was $50.27 \pm 12.17$ with 18 and 76 years as extremes. It is worth noting that males were predominant, with a sex ratio of 1.69 . Uneducated patients accounted for $12.50 \%$. The other socio-economic characteristics were found in Table 1. 


\subsubsection{Etiologies of Kidney Disease}

Nephroangiosclerosis and diabetic nephropathy were respectively the first and second cause of chronic kidney disease, with respectively $25.58 \%$ and $15.19 \%$. Other etiologies are found on Figure 1.

Table 1. Socio-economic characteristics of the population.

\begin{tabular}{|c|c|c|}
\hline & Effective $\mathrm{N}=131$ & Percentage \\
\hline \multicolumn{3}{|l|}{ Age } \\
\hline $18-38$ & 23 & 18 \\
\hline $38-58$ & 69 & 52.4 \\
\hline $58-76$ & 39 & 29.6 \\
\hline \multicolumn{3}{|l|}{ Sex } \\
\hline Male & 82 & 62.88 \\
\hline Female & 49 & 37.12 \\
\hline \multicolumn{3}{|l|}{ Level of education } \\
\hline Out-of-school & 16 & 12.50 \\
\hline Primary & 24 & 18.75 \\
\hline Secondary & 46 & 35.94 \\
\hline Tertiary & 42 & 32.81 \\
\hline \multicolumn{3}{|l|}{ Occupational status } \\
\hline With a profession & 47 & 40.87 \\
\hline Pensioners & 42 & 36.52 \\
\hline Without a profession & 26 & 22.61 \\
\hline \multicolumn{3}{|l|}{ Marital status } \\
\hline Married & 95 & 72.73 \\
\hline Unmarried & 36 & 27.27 \\
\hline \multicolumn{3}{|l|}{ Benefit from a PEC* } \\
\hline Yes & 131 & 100 \\
\hline \multicolumn{3}{|l|}{ Standard of living } \\
\hline High & 38 & 06.82 \\
\hline Average & 84 & 64.39 \\
\hline Low & 09 & 28.79 \\
\hline
\end{tabular}

*Benefit from free haemodialysis provided by the Government of Benin.

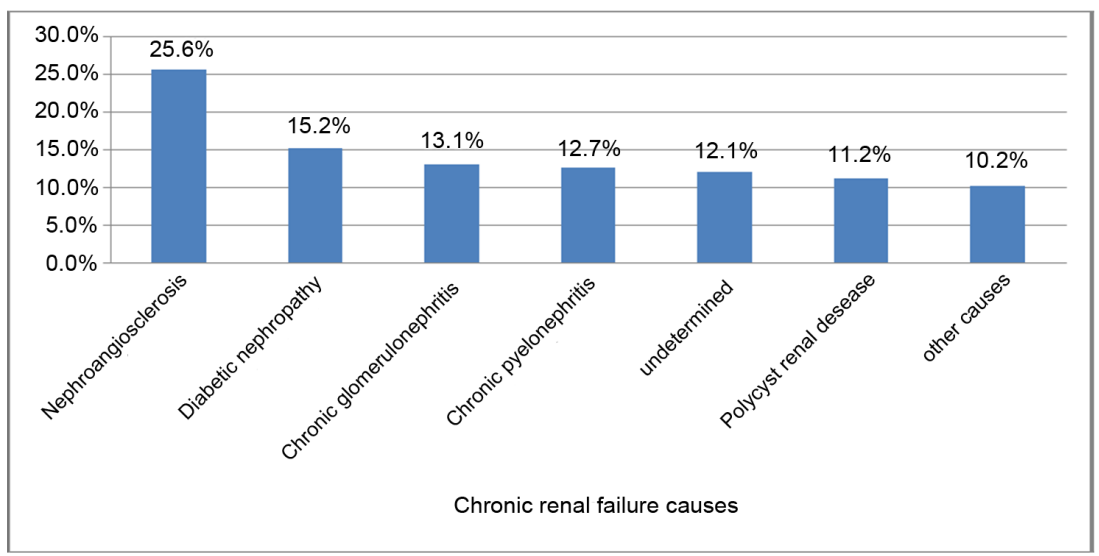

Figure 1. Patients classification per different kidney disease etiologies. 


\subsubsection{Required Haemodialysis Parametres}

Only 3 patients received 3 haemodialysis sessions on weekly basis. And all our patients had an arteriovenous fistula as shown in Table 2.

\subsubsection{Complications of the Patients}

Frequents complications were dominated by anaemia (72.51\%) and infection (35.51\%). Table 3 showed the frequent complications of our patients.

\subsection{Overall Assessment of Hemodialytic Patients Quality of Life}

The average of SF 36 and AOS of KDQoL Overall Average Score (AOS) was 53.55. The different domains average scores ranged from 27.46 to 80.44 as shown in Table 4.

\subsection{Factors Affecting Quality of Life}

According to the generic module, vitality, limitations due to mental health and physical condition were factors that affect hemodialytic patients' quality of life of in CNHU-HKM of Cotonou (Figure 2).

Depending on the specific module, occupational status, burden of the disease and consequences of kidney disease on daily life together with those found in the generic module, constituted factors which adversely affect the quality of life of hemodialytic patients in CNHU HKM-Cotonou (Figure 3).

\subsection{Correlations between Different Domains and Epidemioclinical Data}

- Patients education level was significantly correlated with vitality $(\mathrm{p}<0.017)$;

- Patients number of haemodialyses sessions was significantly correlated with the effects of kidney disease on daily life $(\mathrm{p}<0.025)$;

- Patients' living standard was significantly correlated with physical functioning $(\mathrm{p}<0.020)$;

- Patients occupational status was significantly correlated with cognitive functions ( $p<0.001)$;

Table 2. Patients classification per required haemodialysis parameters.

\begin{tabular}{lcc}
\hline & Effective $\mathbf{N}=\mathbf{1 3 1}$ & Percentage \\
\hline Number of weekly sessions & & 97.71 \\
-2 & 3 & 2.29 \\
$-\quad 3$ & 128 & 100 \\
Type of vascular access & 131 \\
$-\quad$ Arteriovenous fistula & & \\
\hline
\end{tabular}

Table 3. Frequent complications of the patients.

\begin{tabular}{ccc}
\hline & Effective N = 131 & Percentage \\
\hline Anemia & 95 & 72.51 \\
Infection (lung, urinary, otolaryngology) & 46 & 35.11 \\
Carpal chennal syndrom & 35 & 26.71 \\
Hepatitis C & 31 & 23.66 \\
Hyperkaliemia & 28 & 21.37 \\
Undernutrition & 23 & 17.55 \\
Malaria & 12 & 09.16 \\
Unchecked high blood pression & 12 & 09.16 \\
Hepatitis B & 08 & 06.10 \\
Dysfonction of vascular access & 04 & 03.05 \\
\hline
\end{tabular}


Table 4. Average scores for different domains and dimensions.

\begin{tabular}{|c|c|c|}
\hline KDQoL and SF 36 domains & Average score & Standard deviation \\
\hline \multicolumn{3}{|l|}{ - $\quad$ SF 36} \\
\hline General Health (D1) & 52.84 & \pm 19.69 \\
\hline Physical activities (D2) & 50.39 & \pm 23.51 \\
\hline Limitations due to physical conditions (D3) & 27.46 & \pm 35.34 \\
\hline Limitations due to mental state (D4) & 31.57 & \pm 39.85 \\
\hline Life and relationship with others (D5) & 62.45 & \pm 23.05 \\
\hline Mental pain (D6) & 55.47 & \pm 24.44 \\
\hline Vitality (D7) & 46.70 & \pm 16.33 \\
\hline Mental health (D8) & 50.09 & \pm 19.32 \\
\hline Physical Health Dimension (PHD) & 46.54 & \pm 25.75 \\
\hline Mental Health Dimension (MHD) & 47.70 & \pm 24.64 \\
\hline AOS of SF36 & 48.55 & \pm 16.85 \\
\hline - KDQoL & & \\
\hline Burden of illness (D9) & 38.07 & \pm 25.11 \\
\hline Quality of immediate circle (D10) & 62.10 & \pm 14.89 \\
\hline Cognitive functions (D11) & 70.18 & \pm 18.29 \\
\hline Symptoms/problems (D12) & 66.98 & \pm 18.26 \\
\hline Effects of the disease on daily life (D13) & 47.43 & \pm 22.19 \\
\hline Quality of sexual activity (D14) & 55.21 & \pm 33.64 \\
\hline Sleep (D15) & 56.66 & \pm 15.60 \\
\hline Family and friendly relationship (D16) & 62.75 & \pm 28.12 \\
\hline Occupational status (D17) & 45.45 & \pm 29.16 \\
\hline Patient’s satisfaction (D18) & 58.79 & \pm 16.65 \\
\hline Encouragement from dialysis team (D19) & 80.44 & \pm 21.07 \\
\hline Physical Health Dimension (PHD) & 46.54 & \pm 17.55 \\
\hline Mental Health Dimension (MHD) & 50.56 & \pm 17.74 \\
\hline Specific Dialysis Dimension (SDD) & 56.79 & \pm 15.30 \\
\hline Patient Satisfaction Dimension (PSD) & 69.09 & \pm 15.35 \\
\hline AOS of KDQoL & 58.55 & \pm 22.09 \\
\hline
\end{tabular}

- Patients sex was respectively significantly correlated with vitality and symptoms/problems (p $<0.043$ and $\mathrm{p}$ $<0.008)$;

- Patients marital status was significantly correlated with vitality and support from healthcare team (p $<0.008$ and $\mathrm{p}<0.009$ ).

Patients age was respectively significantly correlated with physical functioning, physical pain, perceived health and sexual function ( $\mathrm{p}<0.005, \mathrm{p}<0.047, \mathrm{p}<0.019$ and $\mathrm{p}<0.000$ ) (see Table 4).

Table 5 shows domains which were statistically significant correlated with epidemioclinical variables. 


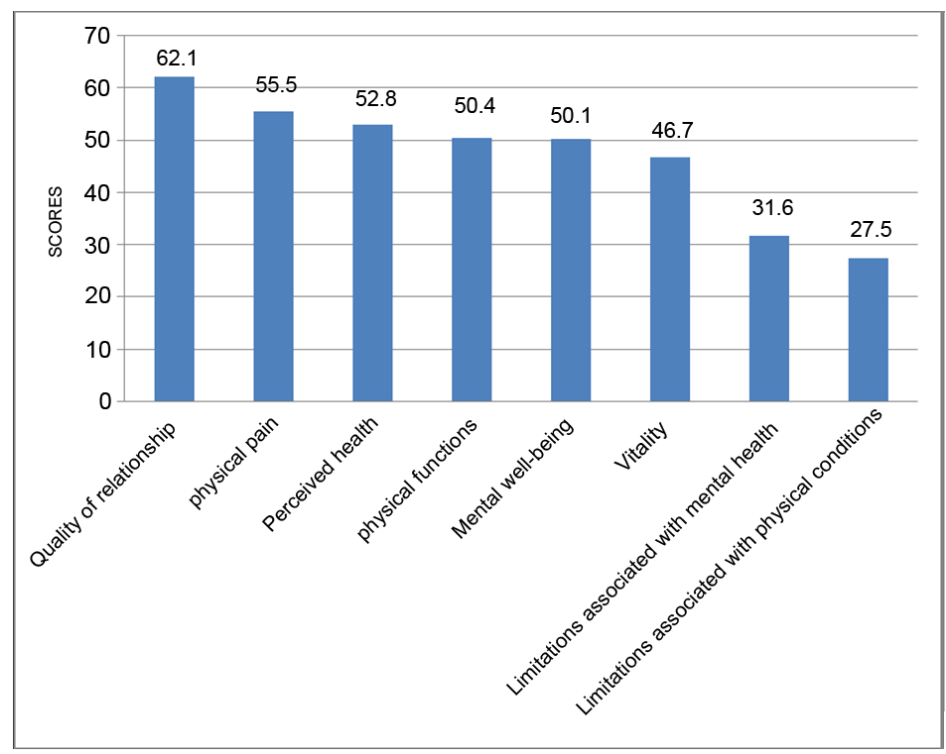

Figure 2. Average Scores for haemodialytic patients SF-36 domains.

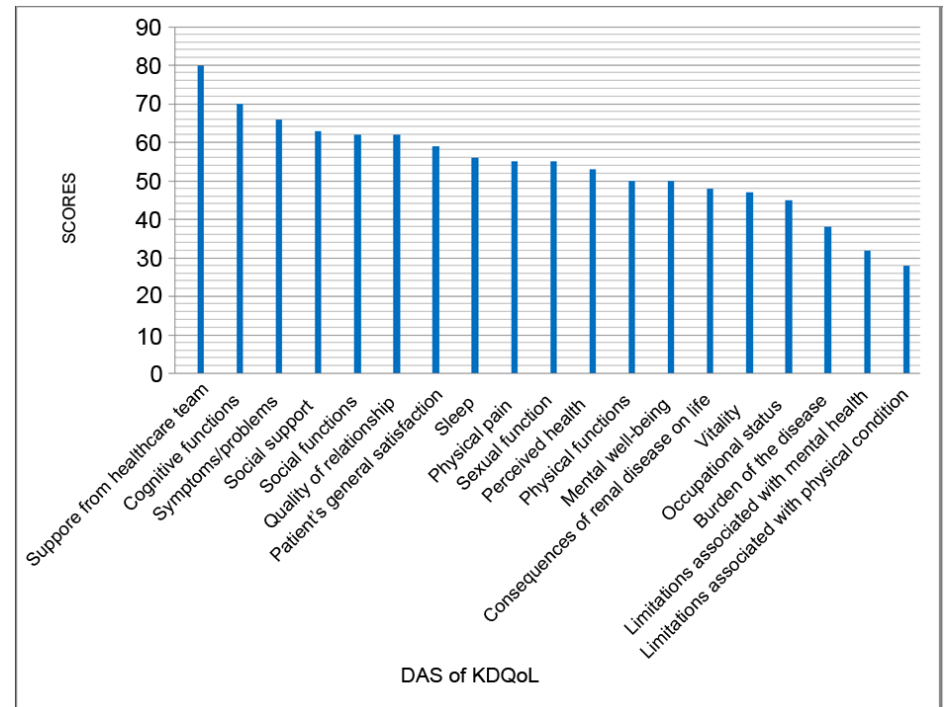

Figure 3. Average scores of haemodialytic patients KDQoL domains.

Table 5. Correlation between epidemioclinical characteristics and KDQoL domains.

\begin{tabular}{|c|c|c|c|c|c|c|c|c|c|}
\hline & D1 & D2 & D6 & D7 & D11 & D12 & D13 & D14 & D19 \\
\hline Level of education & & & & $0.017^{*}$ & & & & & \\
\hline Age & $0.019^{*}$ & $0.005^{* *}$ & $0.047^{*}$ & & & & & $0.000^{* *}$ & \\
\hline Sex & & & & $0.043^{*}$ & & $0.008^{* *}$ & & & \\
\hline Number of sessions & & & & & & & $0.025^{*}$ & & \\
\hline Marital status & & & & $0.008^{* *}$ & & & & & $0.009^{* *}$ \\
\hline Occupational status & & & & & $0.001^{* *}$ & & & & \\
\hline Standard of living & & $0.020^{*}$ & & & & & & & \\
\hline
\end{tabular}

${ }^{* *}$ Correlation is significant at 0.01 level; ${ }^{*}$ Correlation is significant at 0.05 level. 


\section{Discussion}

Nowadays, Quality of Life (QoL) assessment is very interesting in haemodialysis therapeutic programmes. All surveys were mainly facing problems of non homogeneity of study populations, and the choice of the evaluation tool to use. It is the French version of the questionnaire that was used because it has been used repeatedly for studies on quality of life in the African context.

The choice of KDQoL is linked not only to its use in many studies [3] [6]-[9], but also to its specific dimension to dialysis which helps to separate levels of perceived health of dialytic patients from the duration of its execution requiring only 20 to 30 minutes. Its acceptability was good since we only recorded one refusal in our study and also only one missing answer (0.8\%). Bioni et al. [10] in France and Mohamed Nasr et al. [11] in Tunisia respectively found $5.5 \%$ and $32 \%$ missing answers.

\subsection{Overall Quality of Life}

The overall quality of life of haemodialytic patients at CNHU-HKM of Cotonou during the period of our study is average. We found the same result as Ouattara in Senegal in 2008 who found an average overall quality of life evaluated at 50.50 of haemodialytic patients [5]. This could be explained by an average treatment of haemodialytic patients. In France in 2008, Boini found an average quality of life. Furthermore, the author showed that quality of life for haemodialytic patients during the study impaired very much in relation to the general population [10].

\subsection{Factors Affecting Quality of Life of Haemodialytic Patients}

\subsubsection{Per SF 36}

Out of the 08 domains, only 03: namely vitality, limitations related to physical activity and mental activity impaired. Water and food restrictions as well as complexity of treatment could explain severe impairment of the domain "limitations due to physical condition". Figure 4 shows the results of several studies compared to those of this study [11]-[14].

The low Domain Average Score (DAS) of limitations associated with physical conditions, which was observed by most authors, tallies effectively with our results [5] [12]-[14]. Mohamed, N., Jose, A. and Peter, B. observed like this study a low DAS for vitality [11]-[13]. This could be explained by the complexity of the treatment. Moreover, DAS of limitations related to mental health is average in most studies, while it is low in our study [11]-[14]. This could be explained by anxiety for dialysis and insufficient psychological support probably due to the absence of a psychologist in our team. With regard to the physical health dimension of our study, our patients' quality of life was higher when compared to that of Jose, A. and Peter, B. who found 35.2 and 33.3 respectively, while mental health dimension was like those of Jose, A. and Peter, B. respectively 47.9 and 47.5 [12] [13].

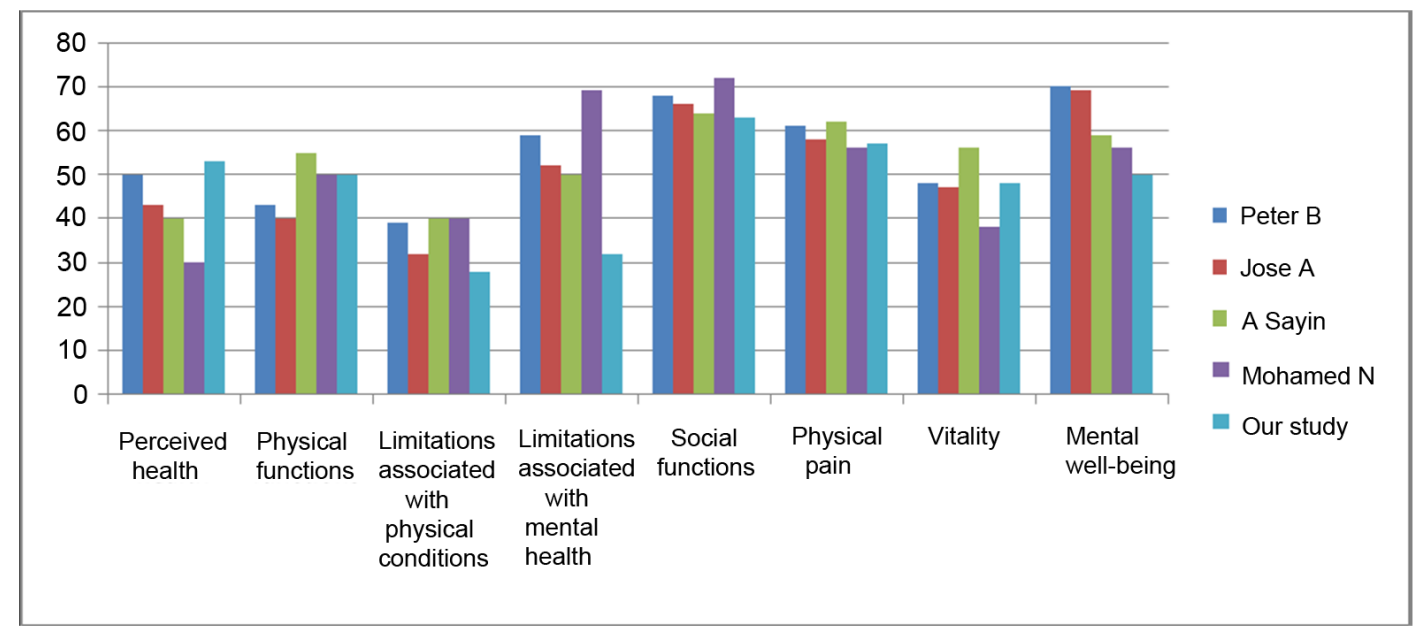

Figure 4. Study histograms comparing quality of life per SF-36. 
The two SF-36 dimensions impaired but physical dimension was a bit more impaired than the mental dimension. This observation was made by several authors [5] [15]. These results could be explained by the following factors: Physical inactivity, damage of the musculoskeletal system, low dose of dialysis, anaemia.

Globally, our haemodialytic patients DAS of KDQoL were comparable to those in the study of Boini Stephanie and Mohamed Nasr [10] [11] except for domains namely "limitations due to mental state", "limitations due to physical activity" and "quality of sexual activity" (Figure 5).

Indeed, it appears that our patients had better sex quality than those of Mohamed and Boini; however, they were more limited physically and mentally compared to Stephanie Boini and Mohamed Nasr's patients [10] [11]. Anaemia associated with dialysis could explain these results.

\subsubsection{Per KDQoL}

The analysis of KDQoL scores dimensions showed similar results to those found by Boini Stephanie and Mohamed Nasr [10] [11], except that mental health dimension (MHD) score is higher in the Tunisian study, and patient satisfaction dimension (PSD) score is higher in the French study (Figure 6).

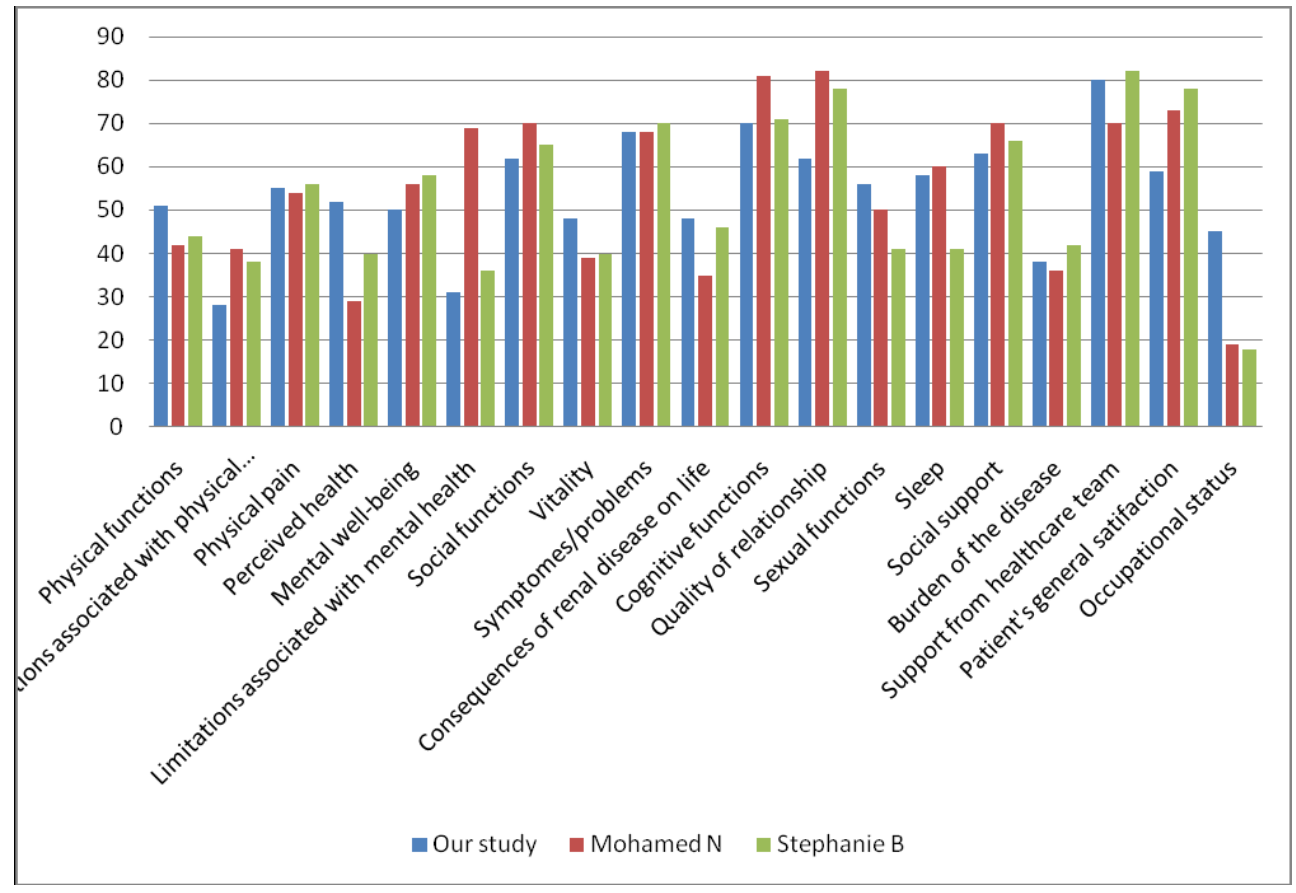

Figure 5. Study histogram comparing quality of life per KDQoL.

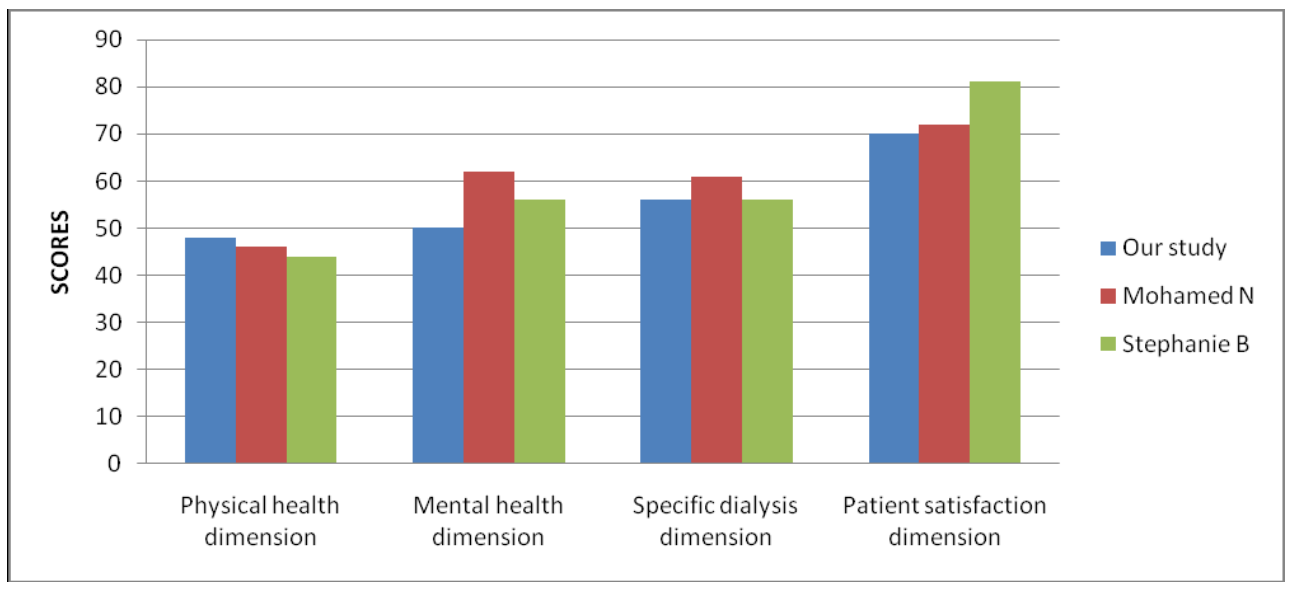

Figure 6. Study histograms comparing different KDQoL dimensions. 


\subsection{Correlation between Quality of Life and Patients Epidemioclinical Characteristics}

Age was correlated with physical functioning, physical pain, perceived health and sexual functions. Literature reports that a higher age is correlated with these domains. This could be explained by a deterioration of physical health and a decline in general adaptive capacity with growing age [11] [14] [15].

Patients education level was correlated with vitality. Low education levels associated with impairment of quality of life (QoL) were found by Mohamed Nasr and Valderrabano who highlighted that a high level of education protects against impairment of QoL [11] [16].

With regard to marital status, Neto observed that married haemodialytic patients had better QoL [17]. Indeed, the presence of the spouse helps the patient to overcome difficulties associated with renal disease [11]. In our study, patients marital status is correlated with vitality and also with support from healthcare team. This could be explained by the fact that haemodialytic patients recognize the support provided to them by healthcare team.

With regard to sex, Sayin, A. found in his study that women had high scores compared to men [14]. Other authors on the contrary, reported that female sex was associated with QoL impairment [11] [15] [16].

To some extent, QoL is influenced by inadequate number of dialyses sessions. We believed that the inadequate number of generators could explain this result. It is therefore logical that patients with inadequate dialysis dose had a slightly impaired QoL than others.

\section{Conclusions}

The overall assessment of chronic haemodialysis patients' quality of life at CNHU-HKM of Cotonou is broadly average (53.55). Factors impairing the quality of life of haemodialysis patients are according to SF36: vitality and limitations related to mental health and physical condition; and according to KDQoL: burden of kidney disease, effect of the disease on daily life and occupational status.

Age was correlated with physical functioning, physical pain, perceived health and sexual functions. Patients education level was correlated with vitality. Patients number of haemodialyses sessions was correlated with the effects of kidney disease on daily life. Patients occupational status was correlated with cognitive functions.

The recourse to the haemodiafiltration online and the increase of the number of the sessions will contribute to improve the quality of life of these patients. It has the advantage to offer a better tolerance. It's associated with a reduction of the carpal channel and of the mortality.

In the same way, it is necessary to increase staff by providing a psychologist and a dietician, and to build new haemodialysis centres in the city.

\section{Disclosure of Conflict of Interest}

None.

\section{References}

[1] MerkusM.P.,Jager, K.J., Dekker, F., Boeschoten, E.W., Stevens, P. and Krediet, R.T. (1997) Quality of Life in Patients on Chronic Dialysis: Self-Assessment 3 Months after the Start of Treatment. American Journal of Kidney Dis- eases, 29, 584-592. http://dx.doi.org/10.1016/S0272-6386(97)90342-5

[2] Boini, S., Leplege, A., Loos, C., Français, P., Ecosse, E. and Briançon, S. (2007) Mesure de la qualité de vie dans l'insuffisance rénale chronique terminale. Adaptation transculturelle et validation du questionnaire spécifique kidney disease quality of life. Néphrologie et Thérapeutique, 3, 372-383. http://dx.doi.org/10.1016/j.nephro.2007.05.005

[3] Hays, R.D., Kallich, J.D., Mapes, D.L., Coons, S.J., Amin, N. and Carter, W.B. (1994) Development of the Kidney Disease Quality of Life (KDQOL) Instrument. Quality of Life Research, 3, 329-338. http://dx.doi.org/10.1007/BF00451725

[4] Martin, P. and Ferreri, M. (1997) Le concept de qualité de vie. Ardix Medical, 45, 345-375.

[5] Ouattara, F. (2008) Qualité de vie des hémodialysés à dakar. Thèse Med, Dakar, No. 120.

[6] Korevaar, J.C., Jansen, M., Merkus, M.P., Dekker, F.W. and Boeschoten, E.W. (2000) Quality of Life in Predialysis End-Stage Disease Patients at the Initiation of Dialysis Therapy. Peritoneal Dialysis International, 20, 69-75.

[7] Gentile, S., Delarozière, J.-Ch., Fernandez, C., Tardieu, S., Devictor, B., Dussol, B., Daurès, J.-P., Berland, Y. and Sambuc, R. (2003) Qualité de vie et insuffisance rénale chronique terminale: Le point sur les différents questionnaires existants. Néphrologie, 24, 291-299. 
[8] Rebollo, P., Ortega, F. and Baltar, J.M. (2001) Is the Loss of Health-Related Quality of Life during Renal Replacement Therapy Lower in Elderly Patients than in Younger Patients? Nephrology Dialysis Transplantation, 16, 1675-1680. http://dx.doi.org/10.1093/ndt/16.8.1675

[9] Wu, A.W., Fink, N.E., Cagney, K.A., Bass, E.B. and Rubin, H.R. (2001) Developing a Health-Related Quality-of-Life Measure for End Stage Renal Disease: The Choice Health Experience Questionnaire. The American Journal of Kidney Diseases, 37, 11-21.

[10] Boini, S., Bloch, J. and Briançon, S. (2011) Surveillance de la qualité de vie des sujets atteints d'insuffisance rénale chronique terminale. Néphrologie et Thérapeutique, 7, S215-S300. http://dx.doi.org/10.1016/S1769-7255(11)70021-9

[11] Mohamed, N., Mohamed, H.A., Sami, K., Dhia, N.B. and Anouar, G. (2008) L’hémodialyse et son impact sur la qualité de vie. Néphrologie et Thérapeutique, 4, 21-27. http://dx.doi.org/10.1016/j.nephro.2007.07.008

[12] Jose, A.D.B., Edmund, G.L. and Nancy, L.L. (2000) Quality-of-Life Evaluation Using Short Form 36: Comparison in Hemodialysis and Peritoneal Dialysis Patients. American Journal of Kidney Diseases, 35, 293-300.

[13] Peter, B.D. (1997) Hemodialysis Patient-Assessed Functional Health Status Predicts Continued Survival, Hospitalization, and Dialysis-Attendance Compliance. American Journal of Kidney Diseases, 30, 204-212. http://dx.doi.org/10.1016/S0272-6386(97)90053-6

[14] Sayin, A., Mutluay, R. and Sindel, S. (2007) Quality of Life in Hemodialysis, Peritoneal Dialysis, and Transplantation Patients. Transplantation Proceedings, 39, 3047-3053. http://dx.doi.org/10.1016/j.transproceed.2007.09.030

[15] Anca, S., Liviu, S. and Constantin, V. (2008) Factors Affecting the Quality of Life of Haemodialysis Patients from Romania: A Multicentric Study. Nephrology Dialysis Transplantation, 1, 1-4.

[16] Valderrabano, F. (2000) Quality of Life Benefits of Early Anemia Treatment. Nephrology Dialysis Transplantation, 15, 23-28. http://dx.doi.org/10.1093/oxfordjournals.ndt.a027972

[17] Neto, J.F., Ferraz, M.B. and Cendoroglo, M. (2000) Quality of Life at the Initiation of Maintenance Dialysis Treatment-A Comparison between the SF-36 and the KDQ Questionnaires. Quality of Life Research, 9, 101-107. http://dx.doi.org/10.1023/A:1008918609281 
Scientific Research Publishing (SCIRP) is one of the largest Open Access journal publishers. It is currently publishing more than 200 open access, online, peer-reviewed journals covering a wide range of academic disciplines. SCIRP serves the worldwide academic communities and contributes to the progress and application of science with its publication.

Other selected journals from SCIRP are listed as below. Submit your manuscript to us via either submit@scirp.org or Online Submission Portal.
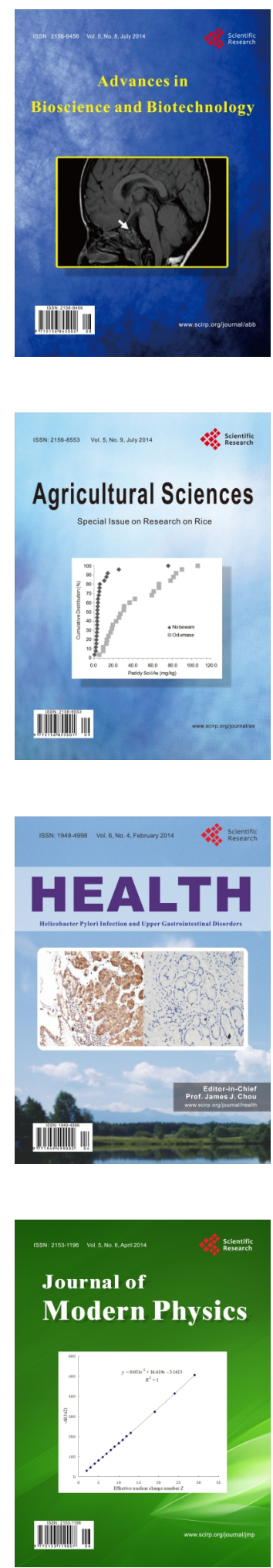
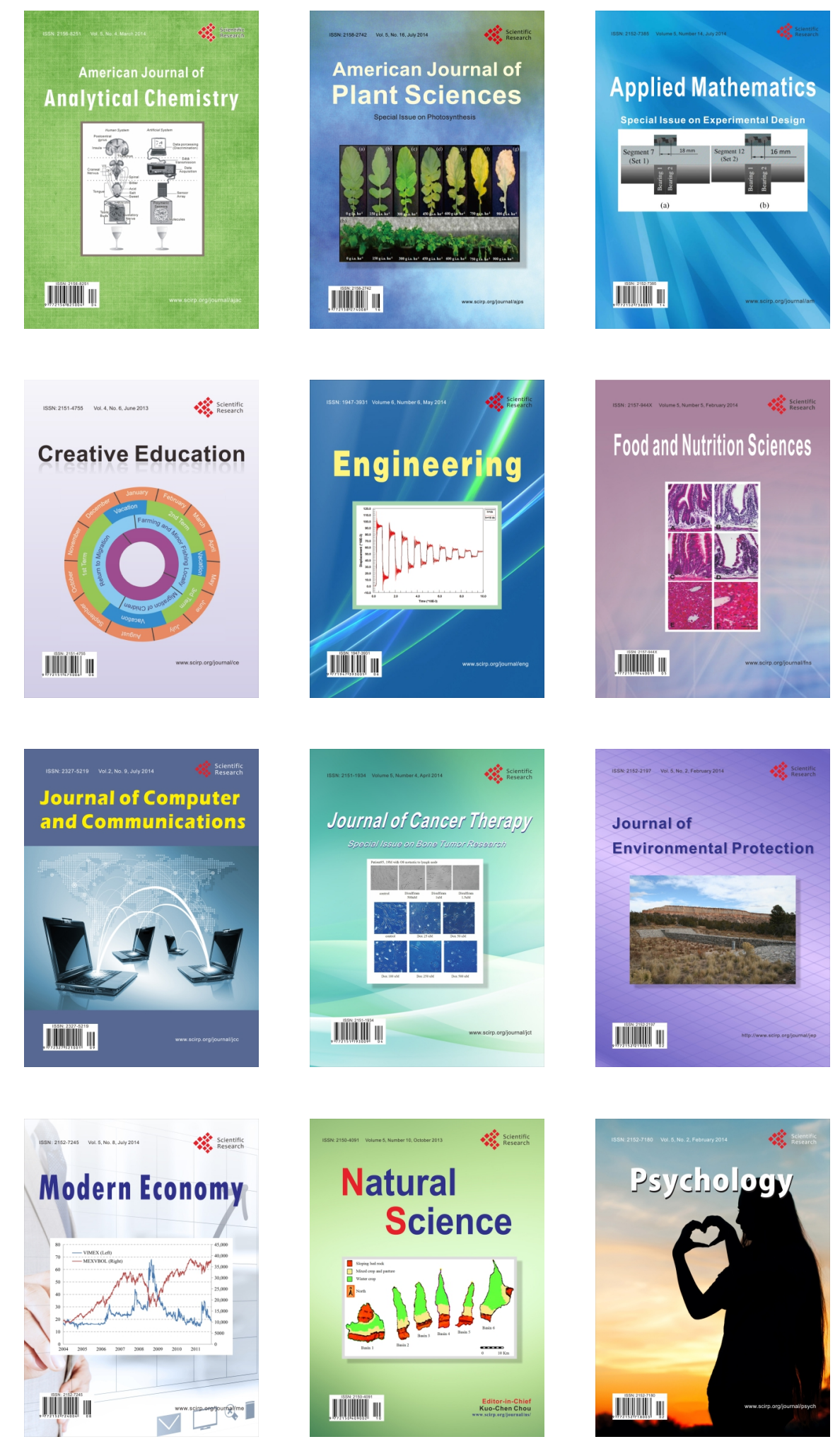